\title{
The influence of particle breakage on stress-dilatancy relationship for granular soils
}

\author{
Zenon Szypcio ${ }^{1, *}$ \\ ${ }^{1}$ Bialystok University of Technology, Faculty of Civil and Environmental Engineering, Wiejska 45E, 15-351 Bialystok, Poland
}

\begin{abstract}
The influence of particle breakage on soil behaviour is important from theoretical and practical perspectives. Particle breakage changes the internal energy in two ways. First, internal energy is consumed for particle crushing and second, the internal energy changes because of additional volumetric strain caused by particle crushing. These two effects may be quantified by use of Frictional State Theory. The analysed drained triaxial compression tests of Toyoura sand, gravel and Dog's Bay sand at different stress level and stress path revealed that the effect of particle breakage is a function of soil gradation, strength of soil grains, stress level and stress path.
\end{abstract}

\section{Introduction}

A detailed understanding of how grain breakage and crushing of grain contacts affects the behaviour of granular soils is important in engineering applications such as the stability of natural slopes, driven piles [1], construction of rockfill structures [2,3], railway base [4,5] and others [6-8]. Particle breakage of granular soil significantly influences soil behaviour $[9,10]$, especially stress-dilatancy behaviour [11]. The most known general stress-dilatancy relationship was developed by Rowe [12] and modernized with consideration of energy consumption by particle breakage by Ueng and Chen [11]. Simple stress-dilatancy relationships were obtained from Cam-Clay [13] and modified Cam-Clay [14] models. The Cam-Clay model was developed by assuming that plastic work is dissipated entirely by friction. The modified Cam-Clay revised the Cam-Clay work equation to include some volumetric dissipation [15]. The critical state line in the q-p' plane is uniquely linear even when breakage occurs [16,17]. For some soils reduce critical stress ratio at high stress level $[3,18$ 20] were observed. The changes in gradation due to particle breakage change the location of the critical state line in the e-log p' plane [21-23].

The stress-plastic dilatancy relationship is important for soil modelling. A general stress-plastic dilatancy relationship was developed based on Frictional State Theory [24]. In this work, the influence of the breakage effect on stress-plastic dilatancy is shown. The energetic equation assumed in Frictional State Theory explains the dual influence of breakage on energy consumption during shear as energy consumption due to the crushing of grain contacts and grain breakage and the change of internal energy due to the volume contraction. These two effects may be quantified by use of Frictional State Theory at the advanced shearing process. For some soils with hard grains this effect is not visible; for some soils, the influence of volume change is dominant, and for others a dual breakage effect is important. This will be shown by analysing previously-published experimental data of drained triaxial compression tests.

\section{Stress-plastic dilatancy for soils}

The general stress-plastic dilatancy for soils [24] has the formula

$$
\eta=Q-A D^{p}
$$

where:

$$
\begin{gathered}
\eta=q / p^{\prime} \\
Q=M^{o}-\alpha A^{o} \\
A=\beta A^{o} \\
D^{p}=\delta \varepsilon_{v}^{p} / \delta \varepsilon_{q}^{p}
\end{gathered}
$$

where $\mathrm{q}$ is deviatoric stress, $\mathrm{p}^{\prime}$ is effective mean stress, and $\alpha$ and $\beta$ are soil parameters.

The plastic parts of volumetric and shear strain increments are calculated from the equations

$$
\begin{aligned}
& \delta \varepsilon_{v}^{p}=\delta \varepsilon_{v}-\delta \varepsilon_{v}^{e} \\
& \delta \varepsilon_{q}^{p}=\delta \varepsilon_{q}-\delta \varepsilon_{q}^{e}
\end{aligned}
$$

where:

$$
\delta \varepsilon_{v}^{e}=\delta p^{\prime} / K
$$

\footnotetext{
*Corresponding author: z.szypcio@pb.edu.pl
} 


$$
\begin{gathered}
\delta \varepsilon_{q}^{e}=\delta q / 3 G \\
K=[2(1+v) / 3(1-2 v)] G
\end{gathered}
$$

where $v$ is Poison's ratio, $\mathrm{G}$ is shear modulus, and $\mathrm{K}$ is bulk modulus.

For granular soils, we can express shear modulus using the equation

$$
G=G_{\mathrm{o}}^{*}\left[\left(2.97-e^{2}\right) /(1+e)\right]\left(p^{\prime} p_{a}\right)^{0.5}
$$

where $\mathrm{G}_{\mathrm{o}}{ }^{*}$ is a soil parameter, $\mathrm{e}$ is the void ratio, and $\mathrm{p}_{\mathrm{a}}$ is atmospheric pressure $(=101 \mathrm{kPa})$.

Using the Cam-Clay model parameter $\kappa$ we can write

$$
\begin{gathered}
G=[3(1-2 v) / 2(1+v)]\left(\vartheta p^{\prime} / \kappa\right) \\
K=(\vartheta / \kappa) p^{\prime}
\end{gathered}
$$

where:

$$
\vartheta=1+e
$$

For drained triaxial compression [24],

$$
M^{o}=M_{c}^{o}=\left(6 \sin \Phi^{\circ}\right) /\left(3-\sin \Phi^{\circ}\right)
$$

where $A^{o}=A_{c}^{o}=1-\left(M_{c}^{o} / 3\right)$ and $\Phi^{\circ}$ is the angle of friction at critical frictional state.

For many granular soils, $\Phi^{\circ}=\Phi^{\prime}{ }_{\mathrm{cu}}$ [24]. Equation (1) expresses a set of straight lines in the $\eta-D^{P}$ plane. The location of this line is defined by Q and slope by A (Fig. $1)$.

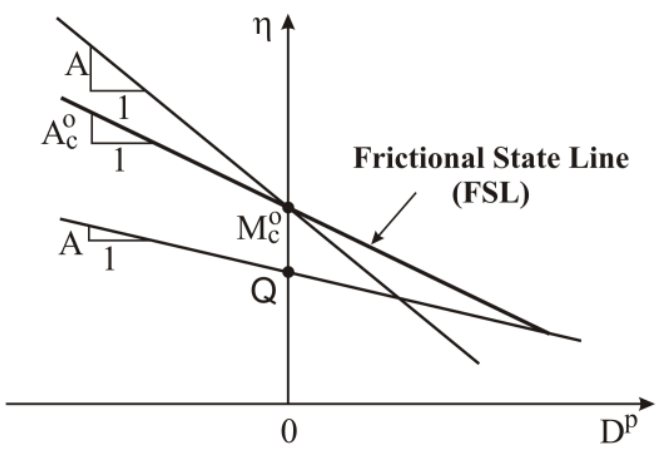

Fig. 1. Stress-plastic dilatancy lines for drained triaxial compression.

In this work, the only drained triaxial tests of samples isotropically consolidated and sheared with constant confining pressure $\left(\sigma_{\mathrm{c}}=\right.$ const. $)$ and constant mean effective stress ( $p^{\prime}=p_{c}=$ const.) are considered (Fig. 2). For those tests, the critical frictional stress state $\mathrm{q}^{\circ}$ and $\mathrm{p}^{\circ}$ are constant during shear and defined by the stress path (Fig. 2). The critical frictional state in the q-p' plane for triaxial compression is represented by a critical frictional state line (CFSL). (a)

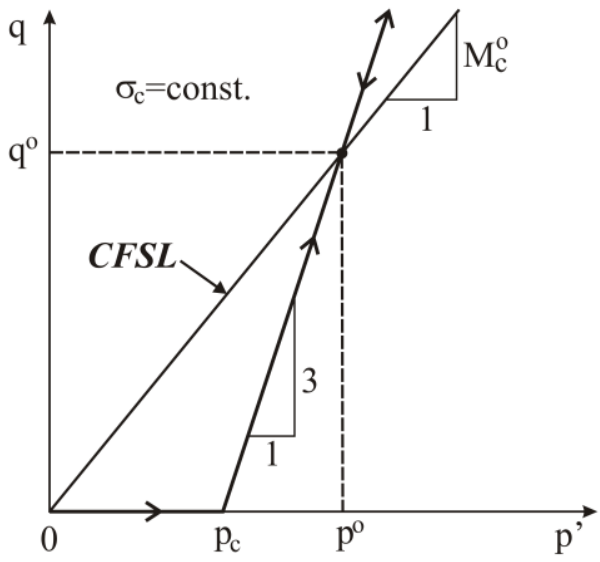

(b)

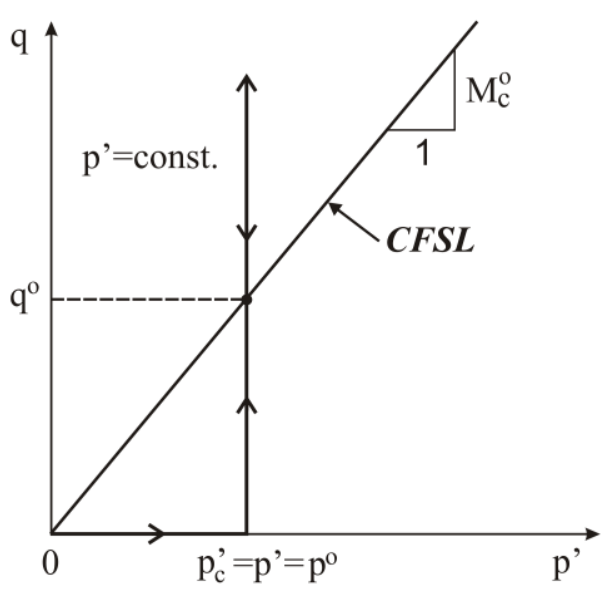

Fig. 2. Scheme of stress path: a) $\sigma_{c}=$ const., b) p'=const.

\section{Energetic considerations}

The equation of energy balance in a soil element has the formula

$$
\delta W=\delta E+\delta D
$$

where $\delta W$ is the total energy of the stresses at the boundary of soil element, $\delta E$ is energy stored as elastic strain energy, and $\delta D$ is energy dissipated in soil element $[25,26]$. The main assumption of Frictional State Theory for triaxial compression is [24]

$$
\delta D=p^{\prime} \delta \varepsilon_{v}^{p n}+q \delta \varepsilon_{q}^{p}=\delta W^{o}=q^{o} \delta \varepsilon_{q}^{p}
$$

where "natural" volumetric strain increment [24] is

$$
\delta \varepsilon_{v}^{p n}=\alpha \delta \varepsilon_{q}+\beta \delta \varepsilon_{v}^{p}
$$

and "natural" plastic dilatancy is

$$
D^{p n}=\alpha+\beta D^{p}
$$

The energy dissipated in soil element, $\delta D$, may be expressed as a sum of energy consumed in a purely frictional state $\delta D_{f}(\alpha=0 ; \beta=1.0)$, energy consumed by material damage during shear $\delta D_{q}$ and energy due to extra changes of volume caused by breakage and 
"unnatural" volume changes due to the complex structure of soils, $\delta D_{v}$. Therefore,

$$
\delta D=\delta D_{f}+\delta D_{q}+\delta D_{v}
$$

where

$$
\begin{gathered}
\delta D_{f}=p^{\prime} \delta \varepsilon_{v}^{p}+q \delta \varepsilon_{q}^{p} \\
\delta D_{q}=\alpha p^{\prime} \delta \varepsilon_{q}^{p} \\
\delta D_{v}=(\beta-1) p^{\prime} \delta \varepsilon_{v}^{p}
\end{gathered}
$$

"Natural" volume changes during shear are treated as changes due to the granular nature of soil exhibited at the frictional state. Therefore, we treat the frictional state as a reference state from the energetic viewpoint.

\section{Stages of stress-plastic dilatancy relationships in drained triaxial tests}

During the initial shearing stage after isotropic consolidation at a small stress level, we can observe soil's elastic behaviour. In this shearing stage, the plastic volumetric and shear strain increments theoretically equal zero and plastic dilatancy (5) cannot be calculated. At a higher stress level, purely elastic behaviour at the initial shearing stage is not observed. The points in the $\eta-D^{P}$ plane for which the onset of plastic deformation is observed are signed as Y (Fig. 3). At further shear deformation, elastic and plastic deformations coexist. The contribution of elastic strain increments remains smaller and that of plastic higher during this shearing stage, which is named stage I. The points representing shear deformation, at which elastic strain increment may be neglected in stress-plastic dilatancy analysis are signed as point $\mathrm{Y}^{*}$ in Fig. 3 . In this shearing stage, $\eta-\mathrm{D}^{\mathrm{P}}$ relationships are linear for many drained triaxial compression tests and are expressed by equation (1) with $\alpha=\alpha_{1}$ and $\beta=\beta_{1}$ values. However, for some shear processes, the relationship $\eta-D^{P}$ is not linear and parameters $\alpha_{1}$ and $\beta_{1}$ cannot be calculated.

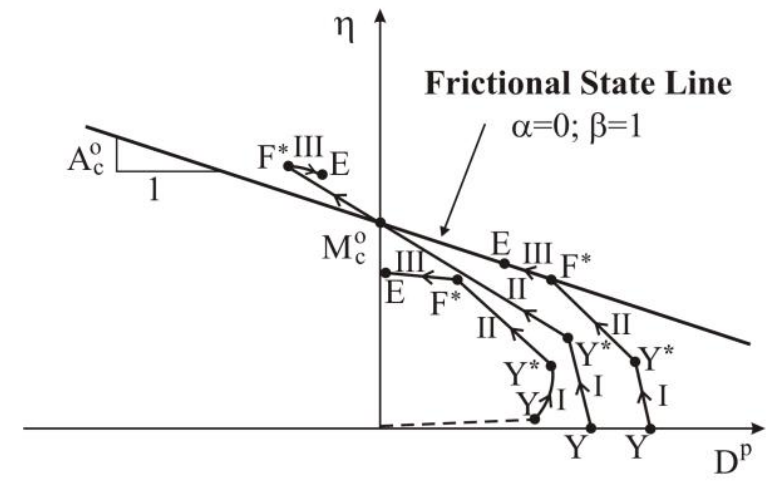

Fig. 3. Typical stages of stress-plastic dilatancy relationships in drained triaxial tests.

At a higher shear level, named stage II, strong destructuration at low stress level and breakage at high stress level are observed. The end of this stage is signed as point $\mathrm{F}^{*}$ in Fig. 3. The segment of the $\eta-\mathrm{D}^{\mathrm{P}}$ line between points $\mathrm{Y}^{*}$ and $\mathrm{F}^{*}$, which represents shearing stage II is defined by equation (1) with $\alpha_{2}$ and $\beta_{2}$ parameters. If there is no breakage effect, $\alpha_{2}=0$ and $\beta_{2}=1$ and this line is a part of FSL [24,28-29], and $\delta D_{q}=\delta D_{v}=0$. If breakage exhibits only changes of volume caused by breakage $D_{q}=0$, then $\delta D_{v}>0 \quad\left(\alpha_{2}=0\right.$, $\beta_{2}>1$ ) [31], but if breakage exhibits not only changes volumetric strain increment $\left(\delta D_{v} \neq 0\right)$ but also the energy of crushing grain contacts and grain breakage $\left(\delta D_{q} \neq 0\right)$,

\begin{tabular}{|c|c|c|c|c|c|c|c|c|c|c|c|c|c|c|}
\hline \multirow{2}{*}{ Reference } & \multirow{2}{*}{ Soil } & \multirow{2}{*}{$\begin{array}{c}\text { Stress } \\
\text { path }\end{array}$} & $\mathbf{e}_{0} / \mathbf{D}_{\mathbf{r}}$ & $\sigma_{\mathbf{c}} / \mathbf{p}_{\mathbf{c}}$ & $\mathbf{G}_{\mathbf{0}}{ }^{*}$ & $\kappa$ & $v$ & $\Phi^{\circ}$ & $\alpha_{1}$ & $\beta_{1}$ & $\alpha_{2}$ & $\beta_{2}$ & $\alpha_{3}$ & $\beta_{3}$ \\
\hline & & & $-/ \%$ & {$[\mathrm{kPa}]$} & {$[-]$} & {$[-]$} & {$[-]$} & {$\left[^{\circ}\right]$} & {$[-]$} & {$[-]$} & {$[-]$} & {$[-]$} & {$[-]$} & {$[-]$} \\
\hline \multirow{3}{*}{$\begin{array}{c}\text { Yao et al. } \\
(2008)\end{array}$} & \multirow{5}{*}{$\begin{array}{c}\text { Toyoura } \\
\text { sand }\end{array}$} & \multirow{4}{*}{$\sigma_{\mathrm{c}}=\mathrm{const}$} & 0.68 & 200 & \multirow{5}{*}{120} & \multirow{5}{*}{ - } & \multirow{5}{*}{0.3} & 31.5 & -0.53 & 3.10 & 0.00 & 1.0 & - & - \\
\hline & & & 0.68 & 1000 & & & & 31.5 & 0,13 & 1.60 & - & - & - & - \\
\hline & & & 0.68 & 2000 & & & & 31.5 & 0.17 & 1.45 & 0.20 & 3.0 & - & - \\
\hline \multirow{2}{*}{$\begin{array}{l}\text { Miura et al. } \\
\quad(1984)\end{array}$} & & & 0.82 & 10000 & & & & 31.5 & 0.00 & 1.00 & - & - & - & - \\
\hline & & $\mathrm{p}_{\mathrm{c}}=\mathrm{const}$ & 0.85 & 1000 & & & & 31.5 & 0.88 & 0.68 & -0.36 & 1.78 & - & - \\
\hline \multirow{3}{*}{$\begin{array}{l}\text { Miranda et } \\
\text { al. (2015) }\end{array}$} & \multirow{3}{*}{ Gravel } & \multirow{3}{*}{$\sigma_{c}=$ const } & \multirow{3}{*}{35} & 50 & \multirow{3}{*}{80} & \multirow{3}{*}{-} & \multirow{3}{*}{0.25} & 41.0 & -13.0 & 25.0 & 0.00 & 1.80 & - & - \\
\hline & & & & 150 & & & & 41.0 & -2.40 & 4.20 & 0.00 & 1.80 & - & - \\
\hline & & & & 300 & & & & 41.0 & -0.55 & 2.20 & 0.00 & 1.80 & - & - \\
\hline \multirow{3}{*}{$\begin{array}{l}\text { Luzzani } \\
\text { and Coop } \\
(2002)\end{array}$} & \multirow{3}{*}{$\begin{array}{l}\text { Dog's } \\
\text { Bay } \\
\text { sand }\end{array}$} & \multirow{2}{*}{$\mathrm{p}_{\mathrm{c}}=\mathrm{const}$} & 1.7 & 100 & \multirow{3}{*}{-} & \multirow{3}{*}{0.0075} & \multirow{3}{*}{0.3} & 42.6 & -0.10 & 4.30 & 0.00 & 2.30 & -0.40 & 1.20 \\
\hline & & & 1.13 & 3286 & & & & 42.6 & - & - & 0.00 & 2.30 & 0.30 & 0.40 \\
\hline & & $\sigma_{\mathrm{c}}=\mathrm{const}$ & 1.00 & 4020 & & & & 42.6 & - & - & 0.00 & 2.30 & 0.65 & 0.40 \\
\hline
\end{tabular}
then $\alpha_{2} \neq 0$ and $\beta_{2} \neq 1[30,32]$. The $\eta-D^{P}$ line for this stage is named the shear tendency line (STL).

Table 1. Experimental condition, elastic and stress-plastic dilatancy parameters 
The last shearing stage (stage III) is represented by a line in the $\eta-D^{P}$ plane by equation (1) with $\alpha_{3}$ and $\beta_{3}$ parameters. Generally, at high stress levels, the strong influence of breakage on the stress-dilatancy relationship is observed [30,32]. At low stress levels, this stage is obtained at large deformation. Non-homogeneity of strains in the sample is often observed and correct analysis of stresses and strains is problematic. Many experiments were interrupted before reaching this stage. Generally, the linear relationships $\eta-D^{P}$ in stages I, II and III are observed and parameters $\alpha_{1}, \beta_{1}, \alpha_{2}, \beta_{2}$ and $\alpha_{3}$, $\beta_{3}$ can be simply calculated. We should remember that destructuration and breakage may coexist at different shearing stages. In the presented approach, these two effects cannot be simply separated.

\section{Methodology of analysis and results}

The published relationships $\mathrm{q}-\varepsilon_{\mathrm{a}}$ and $\varepsilon_{\mathrm{v}}-\varepsilon_{\mathrm{a}}$ for some drained triaxial tests were sectionally approximated by high degree polynomials and the relationship $\eta-D^{P}$ was calculated. The conditions of experiments and elastic parameters taken for analysis are shown in Table 1.

Some drained triaxial compression tests on Toyoura sand conducted by Miura et al. [33] and Yao et al. [34] were analysed. The stress-plastic dilatancy relationships obtained from our analysis are shown in Fig. 4. For clarity, only FSL and characteristic points are shown in Fig. 4. We can see that for sand behaviour at small (dilative) and high stress levels (contractive) at the end of tests, stress-plastic dilatancy is represented by FSL for $\Phi^{\circ}=31.5^{\circ}$. Unexpectedly, for conventional $\left(\sigma_{\mathrm{c}}=10 \mathrm{MPa}=\right.$ const. $)$ drained triaxial compression, it may be assumed that sand behaviour is purely frictional during test $(\alpha=0, \beta=1)$. This means that intensive breakage of sand grains during shear does not exist both for small and high stress (p' $\geq 10 \mathrm{MPa}$ ) levels. The values of parameters $\alpha$ and $\beta$ for different stages of shear are shown in Table 1.

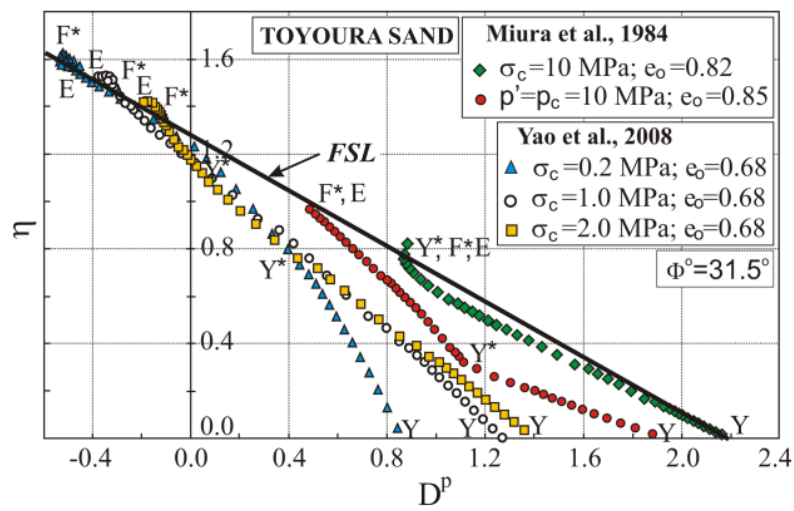

Fig. 4. Stress-plastic dilatancy relationship for Toyoura sand.

The gravel, used as forming material of stone columns, was tested by Miranda et al. [8]. The stressplastic dilatancy relationships obtained from the analysis, based on Frictional State Theory, are shown in Fig. 5. The characteristic points, FSL and shear tendency line (STL) for shearing stage II are shown in Fig. 5. The shear tendency line crosses FSL at $\mathrm{D}^{\mathrm{P}}=0$. Therefore, $\alpha=0$ and STL slope is higher than FSL $(\beta=1.80>1.0)$. This means that at shearing stage II, the effect of volume changes caused by crushing of grain contacts and breakage influence stress-plastic dilatancy relationships. The energy consumed by crushing grain contacts may be negligible $\left(\alpha=0, \delta D_{q}=0\right)$. A more extensive analysis of triaxial tests' data for this gravel is shown in [31].

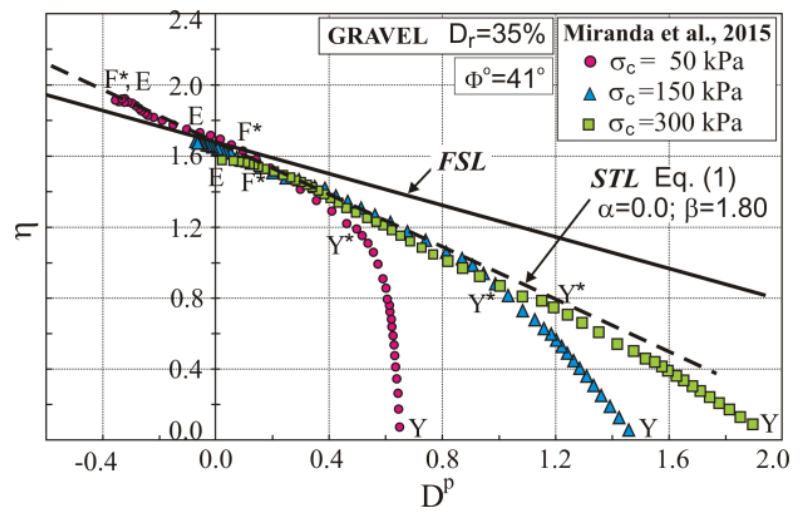

Fig. 5. Stress-plastic dilatancy relationships for gravel.

The tested gravel exhibits a breakage effect at a low stress level.

The calcareous sand was extensively tested [e.g. 8,35-37]. In this paper, only triaxial tests data of Dog's Bay sand [17] were analysed. The obtained stress-plastic dilatancy relationships and the characteristic points are shown in Fig. 6.

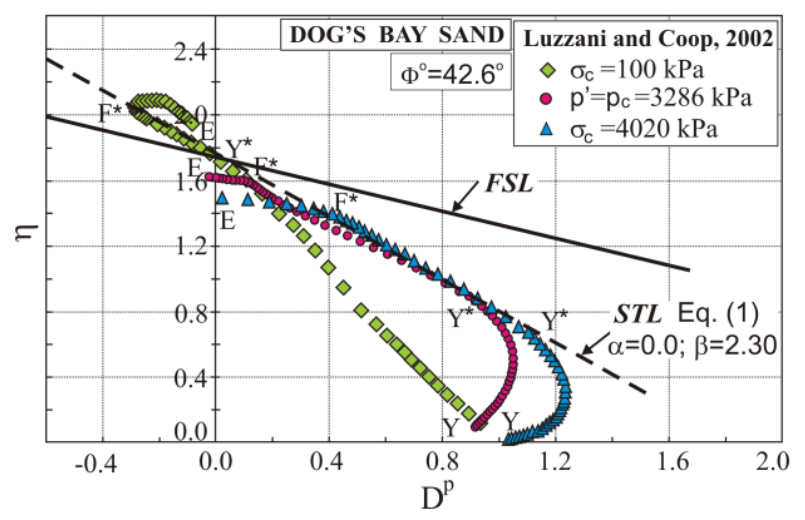

Fig. 6. Stress-plastic dilatancy relationships for Dog's Bay sand.

In shearing stage I, the stress-plastic dilatancy relationship at a high stress level is not linear and parameters $\alpha_{1}$ and $\beta_{1}$ cannot be calculated. At stage II, notwithstanding the stress level, the stress-plastic dilatancy relationships are linear and STL crosses FSL at $\mathrm{D}^{\mathrm{P}}=0$. This means that at stage II, only volume changes caused by breakage influence the stress-plastic dilatancy relationships $(\alpha=0, \beta=2.30>1)$. At shearing stage III, the strong influence of energy consumed for breakage is visible. At this shearing stage at large deformation strains, a constant volume state is reached $\left(\mathrm{D}^{\mathrm{P}}=0\right)$ but at a different stress ratio $\left(Q \neq M_{c}^{o}\right)$ and identification of $\Phi_{c v}^{\prime}$ angle is problematic. 


\section{Conclusion}

The linear stress-plastic dilatancy relationship at different shear stages is observed for particle breakage at a high stress level. The particle breakage effect is a function of soil gradation, strength of soil grains, stress level, and stress path. Particle breakage has a dual effect in energy dissipation during shear, the energy consumption for grain crushing and changes of energy caused by contraction due to particle breakage. These two effects may be quantified by using Frictional State Theory. The problem of particle crushing in a frictional state, assumed as the reference state from an energetic point of view, is theoretically and experimentally open. More theoretical and experimental work is needed to correctly explain the breakage effect on the stress-plastic dilatancy relationship during shear for different soils, stress levels, and stress paths.

\section{References}

1. F. W. Wang, K. Sassa, H. Fakuoka. Soils Found. 40, 35-46 (2000)

2. R. Al-Douri, H. G. Poulos, Int. J. Numer. Anal. Methods Geomech. 25, 49- 59 (1994)

3. Y. Xiao, X. Liu. Int. J. Geomech. 17, 1 (2017)

4. A. Soroush, R. Jannatiaghdam. Int. J. Civil Eng. 10, 2 (2012)

5. B. Indraratna, D. Ionescu, H. D. Christie. J. Geotech. Geoenviron. Eng. 124, 439-450 (1998)

6. B. Indraratna, W. Salim, Proc of 14th Southeast Asian Geotechnical Conference, Hong Kong. Balkema, Vol. 1, 521-526 (2001)

7. M. Miranda, A. Da Costa. Geotext. Geomembr. 44, 269-277 (2016)

8. M. Miranda, A. Da Costa, J. Castro, C. Sagaseta. Can. Geotech. J. 52, 1968-1980 (2015)

9. P. V. Lade, J. A. Yamamuro, P. A. Bopp. J. Geotech. Eng. 122, 309-316 (1996)

10. F. W. Yu. Acta Geotech. Slov. 14, 55-61 (2017)

11. T. -S. Ueng, T. -J. Chen. Géotechnique 50, 1 (2000)

12. P. Rowe. Proc R. Soc. Lond. A, Math. Phys. Eng. Sci. A269, 500-527 (1962)

13. K. H. Roscoe, A. N. Schofield, A. Thurairajah. Géotechnique 13, 211 - 240 (1963)

14. K. H. Roscoe, J. B. Burland. Engineering plasticity, Cambridge University Press (1968)

15. K. J. Hanley, X. Huang, C. O’Sullivan. Géotechnique 68, 421-433 (2018)

16. M. R. Coop, K. K. Sorensen, T. Bodas Freitas, G. Georgoutsos, Géotechnique 54, 157-163 (2004)

17. L. Luzzani, M. R. Coop. Soils Found. 42, 71- 82 (2002)

18. F. W. Yu, Géotechnique 67, 713-719 (2017)

19. C. Chavez, E. E. Alonso. Soils Found. 43, 215-227 (2003)
20. M. Liu, Y. Gao, H. Liu. Int. J. Numer. Anal. Methods Geomech. 38, 935-960 (2014)

21. F. Yu, Int. J. Geomech. 17, 8 (2017)

22. A. B. Fourie, G. Papageorgiou. Can. Geotech. J. 38, 695-706 (2001)

23. T. G. Murthy, D. Loukidis, J. A. H. Carraro, M. Prezzi, R. Salgado, Géotechnique 57, 273-288 (2007)

24. Z. Szypcio. Studia Geotechnica et Mechanica 38, 4 (2016)

25. T. Cuccovillo, M. R. Coop. Géotechnique 49, 6 (1999)

26. M. D. Bolton, Y. Nakata, Y. P. Cheng. Géotechnique 58, 6 (2008)

27. A. Tengattini, A. Das. I. Einav. Géotechnique 66, 9, 2016.

28. K. Dołżyk-Szypcio, Proceedings of China-Europe Conference on Geotechnical Engineering, W. Wu, H. -S. You (Eds) 140-143 (2018)

29. K Dołżyk-Szypcio. Studia Geotechnica et Mechanica 40, 2 (2018)

30. K. Dołżyk-Szypcio. Studia Geotechnica et Mechanica 40, 1 (2018)

31. Z. Szypcio. Ann. Warsaw Univ. of Life Sci. SGGW, Land Reclam. 50, 2 (2018)

32. Z. Szypcio. 108 Conf. Series: Earth and Environmental Science 95 (2017)

33. N. Miura, H. Murata, N. Yasufuku, Soils Found. 24, 1 (1984)

34. Y. P. Yao, H. Yamamoto, N.-D. Wang. Soils Found. 48, 4 (2008)

35. L. L. Colliat - Dangus, J. Desrues, P. Foray. Advanced Triaxial Testing of Soil and Rock, ASTM STP977, 290-310 (1988)

36. M. R. Coop. Géotechnique 40, 4 (1990)

37. M. Hassanlourad, H. Salehzadeh, H. Shahnazari, Int. J. Civil Eng. 6, 2 (2008) 